\title{
Cerebral blood flow, internal carotid artery pressure, and the EEG as a guide to the safety of carotid ligation
}

\author{
P. J. LEECH, J. D. MILlER, W. FITCH, AND J. BARKER \\ From the MRC Cerebral Circulation Research Group, \\ Institute of Neurological Sciences, Glasgow
}

SYNOPSIS Twenty patients with aneurysms of the internal carotid artery underwent temporary clamping, in turn, of the internal and then the common carotid artery. Cerebral blood flow, internal carotid artery pressure, and the EEG were recorded to assess the probability of cerebral ischaemia after permanent ligation. With this method of monitoring the cerebral circulation, 17 of the 20 patients had a permanent carotid ligation without neurological deficit; in the other three ligation was contraindicated. Although a correlation was observed between the reduction of cerebral blood flow and the fall in internal carotid artery pressure caused by temporary clamping $(P<0.01)$, the scatter of data was too wide to predict cerebral blood flow from the change in carotid artery pressure. Similarly, EEG slowing was usually associated with low cerebral blood flow but exceptions occurred Ligation was safe when, during temporary clamping, cerebral blood flow exceeded $40 \mathrm{ml} / 100 \mathrm{~g} / \mathrm{min}$ but was deemed unsafe when flow was less than $20 \mathrm{ml} / 100 \mathrm{~g} / \mathrm{min}$. In the range $20-40 \mathrm{ml} / 100 \mathrm{~g} / \mathrm{min}$ consideration of the internal carotid artery pressure permitted more patients to be safely ligated than if the decision had rested on changes in cerebral blood flow alone.

Permanent ligation of a carotid vessel in the neck is a widely used method of treating certain intracranial aneurysms and recent studies have confirmed its efficacy in providing lasting protection from recurrent subarachnoid haemorrhage (German and Black, 1965; Sahs et al., 1973). Although a more simple operation than intracranial clipping of an aneurysm, it carries the risk of producing ischaemia of the ipsilateral cerebral hemisphere, reported to occur in $30 \%$ of the aggregate series of 785 carotid ligation operations in the Co-operative Aneurysm Study (Nishioka, 1966). In $21 \%$ of these cases the signs of ischaemia were delayed for more than 48 hours after ligation, and recent evidence suggests that deficits of delayed onset are more likely to be permanent than are ischaemic complications occurring in the first few hours after ligation (Landolt and Millikan, 1970). Clearly, a reliable method for predicting which patients will not tolerate ligation is of paramount importance.

Measurement of cerebral blood flow (CBF) during temporary carotid occlusion was proposed as a means of predicting the likelihood of ischaemia following carotid ligation in a preliminary communication from this Institute (Jennett et al., 1966). Four patients who developed signs of ischaemia after carotid ligation had more than $25 \%$ reduction in CBF from control values during temporary carotid clamping; in contrast, the remaining five patients, who showed no evidence of ischaemia, had reduction of less than $25 \%$. It was therefore proposed that permanent ligation of the carotid artery be performed only in patients who had less than $25 \%$ reduction in CBF during temporary clamping.

The result of applying this method in the next 44 patients was a dramatic reduction in the incidence of cerebral ischaemia (to $7 \%$ ) but the cost was the rejection of $39 \%$ of patients for permanent ligation (Jennett et al., 1974). Although such patients are spared the risk of hemiplegia, their original condition remains untreated, and they face the hazard of this and of an alternative 854 
method of treatment. A reappraisal of the criteria for predicting ischaemia was therefore considered desirable. During the management of the next 20 patients it was decided to pay particular attention to absolute values of $\mathrm{CBF}$ during temporary carotid occlusion, and to the relationship between CBF, internal carotid artery pressure (ICAP) and the electroencephalogram (EEG) during temporary carotid clamping.

\section{METHODS}

All 20 patients, whose ages ranged from 18 to 66 years, had aneurysms of the intracranial section of the internal carotid artery. All were alert; 17 had suffered a recent subarachnoid haemorrhage and the other three local symptoms from the aneurysm. Only two were hypertensive at the time of surgery.

PREOPERATIVE STUDIES All patients had bilateral carotid angiography and each underwent a period of three minutes percutaneous carotid compression with EEG monitoring without anaesthesia. If significant focal slowing of EEG activity appeared, the patient was considered an unsuitable candidate for surgery at that time and the procedure postponed.
Surgery was delayed for a week in one patient who developed EEG abnormalities during initial percutaneous carotid compression, but who tolerated this test when it was repeated some days later. In three further patients carotid ligation was not carried out because of EEG changes; two of these died of recurrent haemorrhage before retesting was possible, while the remaining patient had such severe EEG slowing and temporary hemiparesis during digital carotid compression that ligation was considered unwise (vide infra).

ANAESTHESIA In all patients anaesthesia was induced with thiopentone $(350-450 \mathrm{mg}$ ) injected intravenously and maintained with $70 \%$ nitrous oxide and $30 \%$ oxygen. After intubation and insertion of an oesophageal thermocouple lead, intermittent positive pressure ventilation was instituted and the volume of ventilation and the inspired oxygen tension was adjusted to produce normocapnia and normoxia. Muscular paralysis was obtained by the use of a non-depolarizing muscle relaxant. In addition, pentazocine $(30-60 \mathrm{mg})$ was administered where indicated.

OPERATIVE PROCEDURE The carotid bifurcation was exposed using a longitudinal skin incision to allow

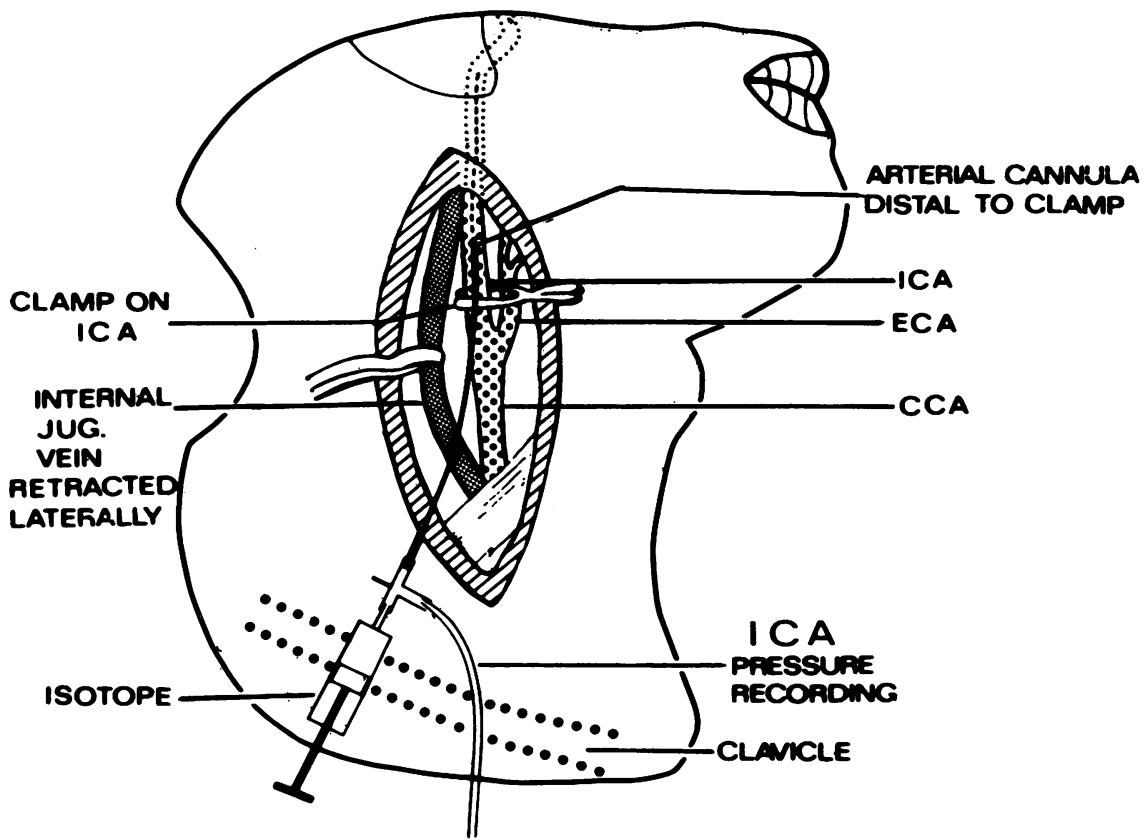

FIG. 1. Surgical exposure showing a temporary clamp on the internal carotid artery (ICA). 
access to the distal $3 \mathrm{~cm}$ of the common carotid artery and the proximal $3 \mathrm{~cm}$ of the internal carotid artery. The internal carotid artery was punctured with an 18 gauge Longdwell catheter (BectonDickenson), $2-3 \mathrm{~cm}$ above the bifurcation to allow later placement of a temporary clamp proximal to the cannula. The cannula was advanced $5-6 \mathrm{~cm}$ until the tip was judged to lie at the base of skull. A three-way tap was attached to the cannula, permitting continuous recording of internal carotid artery pressure to continue during internal or common carotid occlusion, and to allow the introduction of isotope into the cerebral circulation (Fig. 1).

MEASUREMENTS Systemic arterial pressure (SAP) was measured from an indwelling cannula in the radial or dorsalis pedis artery; SAP and ICAP were monitored continuously using arterial range pressure transducers (Elema Schonander EMT-34). End-tidal $\mathrm{CO}_{2}$ was monitored using a URAS-4 infra-red analyser, and arterial blood gases were estimated using a direct reading electrode system (Radiometer BMS-3), normocapnia being checked before each measurement of CBF. Sixteen-channel EEG recordings were made throughout the study using stick-on electrodes and the recordings subjected to manual frequency analysis. Oesophageal temperature was monitored using an electric universal thermometer
(ELLAB), normothermia being maintained with blankets and warmed infusion fluids. Arterial blood gas estimations were corrected for temperature where indicated. Oscilloscopic display and continuous print-out record of the SAP, ICAP, and endtidal $\mathrm{CO}_{2}$ was provided by an 8-channel recorder (Mingograph 81).

CEREBRAL BLOOD FLOW Cerebral blood flow was measured by counting the clearance of $\gamma$ activity from the frontal and temporal regions after the intracarotid bolus injection of $2-3 \mathrm{mc}{ }^{133}$ Xenon in heparinized saline. The data were analysed on-line using a PDP 12 computer, the clearance curve and results being displayed in a data processing laboratory and relayed to the theatre suite using closed circuit television (Wyper and Rowan, 1973).

A first estimate of CBF, based on the initial slope of the clearance curve, was available shortly after injection of the isotope when the count rate fell to half of its initial value. The clamp could be removed at this stage if a particularly slow flow was found. A more accurate value, which was used to assess the probability of ischaemia after ligation, was obtained $+\frac{}{\circ}$ using the height-over-area method after 10 minutes 0 음 clearance of isotope but with the curve extrapolated to infinity (Rowan et al., 1974).
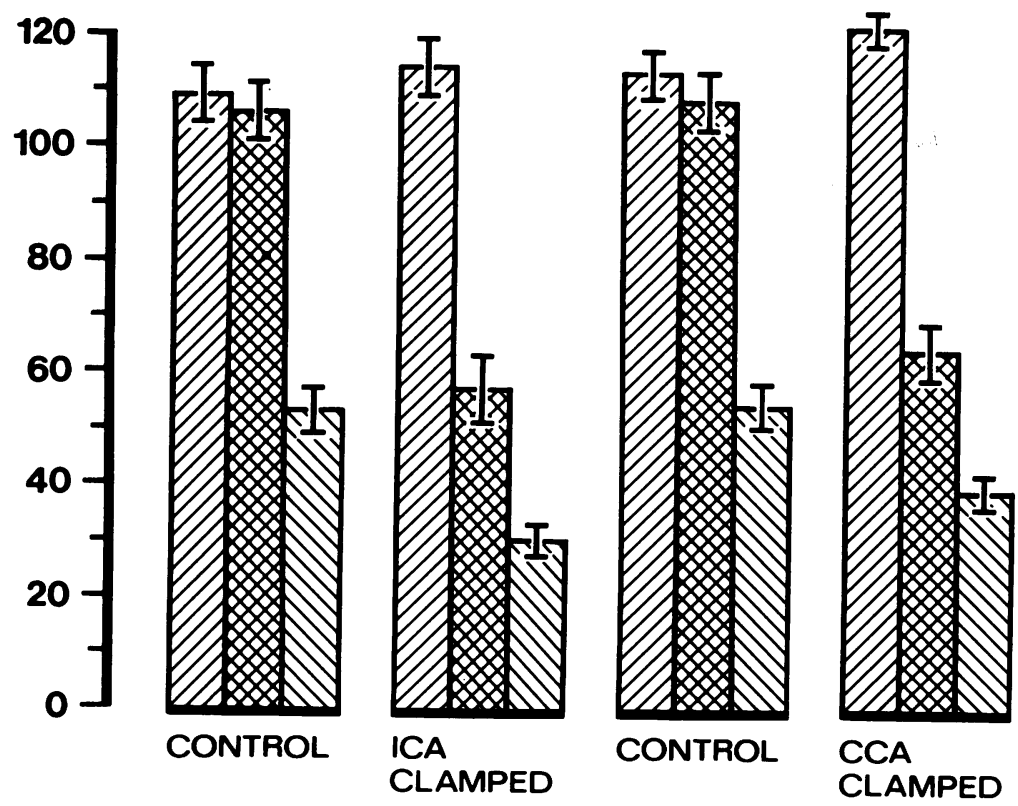

FIG. 2. Systemic arterial pressure $(S A P)$, internal carotid artery pressure (ICAP), and cerebral blood flow (CBF) in control conditions and during temporary clamping

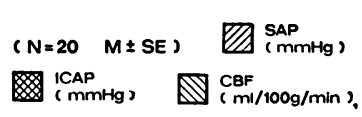


TABLE 1

ARTERIAL $\mathrm{PCO}_{2}$ VALUES DURING CEREBRAL BLOOD FLOW MEASUREMENTS $(\mathrm{N}=20)$

\begin{tabular}{llc}
\hline CBF measurement & $\begin{array}{c}\mathrm{PaCO}_{2}(\mathrm{mmHg}) \\
\mathrm{M} \pm \mathrm{SD}\end{array}$ \\
\hline 1 & Control & $41 \cdot 2 \pm 1 \cdot 1$ \\
2 & ICA clamped & $41 \cdot 6 \pm 1 \cdot 2$ \\
3 & Control & $41 \cdot 5 \pm 1 \cdot 3$ \\
4 & CCA clamped & $41 \cdot 6 \pm 1 \cdot 3$ \\
5 & After ligation & $42 \cdot 0 \pm 1 \cdot 7$ \\
\hline
\end{tabular}

Five successive measurements of $\mathrm{CBF}$ were made:

1. First control, no clamp.

2. Five minutes after a temporary clamp was applied to the internal carotid artery.

3. Second control, no clamp.

4. Five minutes after a temporary clamp was applied to the common carotid artery. From the changes in CBF, ICAP, and EEG during temporary clamping, a decision was taken whether to ligate the internal carotid or the common carotid artery, the vessel showing the lesser changes being selected.

5. After the ligation had been completed.

TABLE 2

CEREBRAL BLOOD FLOW, INTERNAL CAROTID ARTERY PRESSURE AND EEG DURING INTERNAL (ICA) AND COMMON CAROTID (CCA) CLAMPING

\begin{tabular}{|c|c|c|c|c|c|c|c|c|c|c|}
\hline \multicolumn{2}{|c|}{$\begin{array}{l}\text { Patient no. } \\
\text { and clamp }\end{array}$} & \multicolumn{3}{|c|}{$C B F$} & \multicolumn{3}{|c|}{$I C A P$} & \multirow{2}{*}{$\begin{array}{c}\text { EEG } \\
\text { slowing }\end{array}$} & \multirow{2}{*}{$\begin{array}{c}\text { Unsuitable } \\
\text { for } \\
\text { ligation }\end{array}$} & \multirow[t]{2}{*}{ Ligated } \\
\hline & & $\begin{array}{c}\text { Before } \\
\text { clamping } \\
(\mathrm{ml} / \mathrm{l} 03 \mathrm{~g} / \mathrm{min})\end{array}$ & $\begin{array}{c}\text { After } \\
\text { clamping } \\
(\mathrm{ml} / 100 \mathrm{~g} / \mathrm{min})\end{array}$ & $\begin{array}{c}\% \\
\text { Red'n }\end{array}$ & $\begin{array}{l}\text { Before } \\
\text { clamping } \\
(\mathrm{mmHg})\end{array}$ & $\begin{array}{l}\text { After } \\
\text { clamping } \\
(\mathrm{mmHg})\end{array}$ & $\begin{array}{c}\% \\
\text { Red'n }\end{array}$ & & & \\
\hline \multirow[t]{2}{*}{1} & ICA & 38 & 23 & 39 & 105 & 38 & 64 & $x$ & $x$ & \\
\hline & CCA & 46 & 28 & 39 & 101 & 48 & 48 & $x$ & $x$ & \\
\hline \multirow[t]{2}{*}{2} & ICA & 71 & 53 & 20 & 95 & 75 & 21 & & & \\
\hline & CCA & 69 & 66 & 4 & 93 & 74 & 20 & & & $\times$ \\
\hline \multirow[t]{2}{*}{3} & ICA & 55 & 24 & 56 & 121 & 52 & 57 & $x$ & $x$ & \\
\hline & CCA & 69 & 28 & 59 & 111 & 52 & 46 & $x$ & $\times$ & \\
\hline \multirow[t]{2}{*}{4} & ICA & 88 & 35 & 60 & 91 & 44 & 51 & $x$ & $x$ & \\
\hline & CCA & 83 & 51 & 41 & 89 & 52 & 42 & & & $\times$ \\
\hline \multirow[t]{2}{*}{5} & ICA & 52 & 34 & 34 & 96 & 53 & 45 & & $x$ & \\
\hline & $\mathrm{CCA}$ & 53 & 38 & 27 & 99 & 62 & 37 & & & $x$ \\
\hline \multirow[t]{2}{*}{6} & ICA & 75 & 49 & 35 & 115 & 67 & 42 & & & \\
\hline & CCA & 81 & 68 & 17 & 114 & 73 & 35 & & & $x$ \\
\hline \multirow[t]{2}{*}{7} & ICA & 34 & 17 & 50 & 117 & 43 & 63 & $x$ & $x$ & \\
\hline & CCA & 38 & 27 & 24 & 120 & 76 & 36 & & & $\times$ \\
\hline \multirow[t]{2}{*}{8} & ICA & 84 & 39 & 53 & 70 & 48 & 31 & $\times$ & $x$ & \\
\hline & $\mathrm{CCA}$ & 93 & 53 & 43 & 76 & 53 & 30 & & & $x$ \\
\hline \multirow[t]{2}{*}{9} & ICA & 26 & 24 & 8 & 108 & 88 & 18 & & & $x$ \\
\hline & CCA & 27 & 18 & 33 & 112 & 80 & 28 & & $x$ & \\
\hline \multirow[t]{2}{*}{10} & ICA & 84 & 37 & 56 & 97 & 39 & 60 & & $x$ & \\
\hline & $\mathrm{CCA}$ & 94 & 52 & 45 & 115 & 45 & 61 & & & $x$ \\
\hline \multirow{2}{*}{11} & ICA & 75 & 25 & 67 & 115 & 32 & 72 & & $\times$ & \\
\hline & CCA & 64 & 42 & 34 & 109 & 47 & 57 & & & $\times$ \\
\hline \multirow[t]{2}{*}{12} & ICA & 37 & 19 & 49 & 101 & 72 & 29 & $x$ & $\times$ & \\
\hline & $\mathbf{C C A}$ & 41 & 37 & 10 & 101 & 69 & 32 & & & $x$ \\
\hline \multirow[t]{2}{*}{13} & ICA & 54 & 17 & 69 & 91 & 48 & 47 & & $\times$ & \\
\hline & CCA & 45 & 34 & 24 & 83 & 56 & 33 & & & $x$ \\
\hline \multirow[t]{2}{*}{14} & ICA & 43 & 34 & 21 & 93 & 57 & 39 & & & \\
\hline & $\mathrm{CCA}$ & 49 & 39 & 20 & 112 & 72 & 36 & & & $x$ \\
\hline \multirow[t]{2}{*}{15} & ICA & 50 & 37 & 25 & 111 & 44 & 60 & & & \\
\hline & CCA & 50 & 39 & 22 & 107 & 64 & 40 & & & $x$ \\
\hline \multirow[t]{2}{*}{16} & ICA & 38 & 12 & 68 & 108 & 39 & 64 & $x$ & $\times$ & \\
\hline & $\mathrm{CCA}$ & 29 & - & - & 105 & 45 & 57 & $x$ & $x$ & \\
\hline \multirow[t]{2}{*}{17} & ICA & 32 & 37 & -15 & 151 & 132 & 13 & & & $x$ \\
\hline & CCA & 37 & 12 & 68 & 160 & 129 & 19 & $x$ & $x$ & \\
\hline 18 & ICA & 33 & 22 & 33 & 151 & 64 & 58 & & & \\
\hline & CCA & 36 & 34 & 6 & 129 & 75 & 42 & & & $\times$ \\
\hline 19 & ICA & 42 & 43 & -2 & 104 & 63 & 32 & & & $x$ \\
\hline & CCA & 46 & 41 & 10 & 126 & 67 & 38 & & & \\
\hline 20 & ICA & 47 & 33 & 30 & 107 & 33 & 69 & & $x$ & \\
\hline & CCA & 45 & 39 & 13 & 104 & 41 & 61 & & & $\times$ \\
\hline
\end{tabular}




\section{RESULTS}

SAP and $\mathrm{PaCO}_{2}$ were maintained steady throughout each study (Fig. 2; Table 1).

CEREBRAL BLOOD FLOW During temporary clamping of the internal carotid artery, mean CBF was reduced from $52 \cdot 9 \pm 4 \cdot 4$ to $30 \cdot 7 \pm 2 \cdot 5$ $\mathrm{ml} / 100 \mathrm{~g} / \mathrm{min}(42 \%)$ and during clamping of the common carotid artery from $54 \cdot 7 \pm 4.6$ to $39 \cdot 3 \pm$ $3.3 \mathrm{ml} / 100 \mathrm{~g} / \mathrm{min}(28 \%)$. The difference between the first and second control measurements was not significant, but CBF was reduced significantly less during common carotid clamping than during clamping of the internal carotid artery $(\mathrm{P}<0.01$; Fig. 2). Individual results are shown in Table 2.

INTERNAL CAROTID ARTERY PRESSURE Temporary occlusion of the internal carotid artery reduced ICAP from $106 \cdot 3+4.9$ to $57 \cdot 1 \pm 6 \cdot 0$ $\mathrm{mmHg}(46 \%)$, and during common carotid artery clamping from $108 \cdot 9 \pm 4 \cdot 7$ to $64 \cdot 1 \pm 5 \cdot 2$ $\mathrm{mmHg}(41 \%)$ (Table 2). Again, the difference between the control values was not significant, but ICAP with the common carotid artery clamped was significantly higher during temporary occlusion of the internal carotid artery

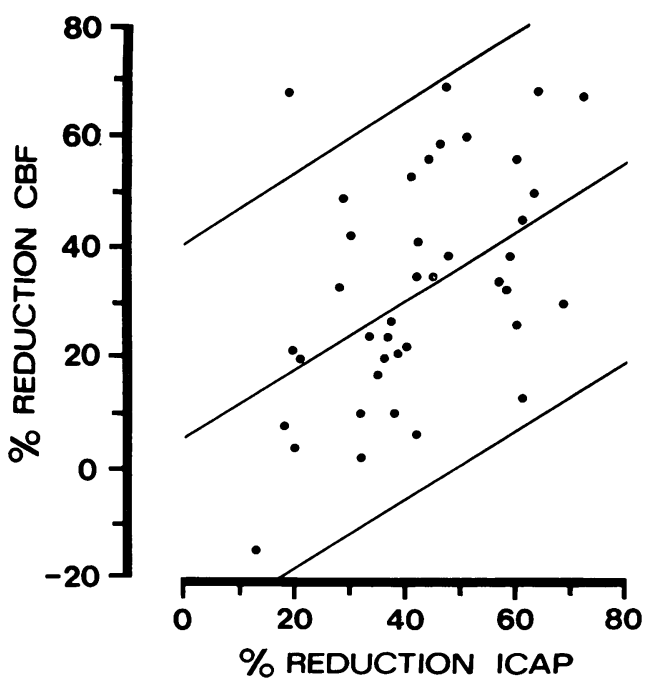

FIG. 3. Reduction in mean $C B F$ and mean ICAP during temporary clamping. $y=5.4+0.6 x, r=0.46$, $P<0.01,2 S y_{x}=36 \%$.

\section{TABLE 3}

CEREBRAL BLOOD FLOW (CBF) AND INTERNAL CAROTID ARTERY PRESSURE (ICAP) AND EEG SLOWING DURING TEMPORARY CLAMPING

\begin{tabular}{lcc}
\hline & $\begin{array}{c}C B F \\
(m l / 100 \mathrm{~g} / \mathrm{min}) \\
M \pm S E\end{array}$ & $\begin{array}{c}I C A P \\
(\mathrm{mmHg}) \\
M \pm S E\end{array}$ \\
\hline No focal EEG change $(\mathrm{N}=29)$ & $38 \cdot 7 \pm 2 \cdot 3$ & $62 \cdot 1 \pm 3 \cdot 7$ \\
Focal EEG slowing $(\mathrm{N}=11)$ & $26 \cdot 2 \pm 2 \cdot 8$ & $55 \cdot 4 \pm 7 \cdot 8$ \\
& $\mathrm{P}<0 \cdot 01$ & $\mathrm{NS}$ \\
\hline
\end{tabular}

( $P<0.01$; Fig. 2). Although a significant linear correlation was obtained between the percentage reductions from control values of CBF and ICAP $(\mathrm{P}<0.01 ; r=0.46)$, the $95 \%$ confidence limits were too wide to determine accurately the fall in CBF from the fall in ICAP (2Syx $=36 \%$; Fig. 3$)$.

Measurement of ICAP during this procedure confers several technical advantages. Demonstra=o tion of wave form on the oscilloscope confirms cannula patency and the sharp fall in pressure during temporary clamping or permanent liga@ tion is evidence of complete vessel occlusion? During the first few minutes after clamp applica tion, the ICAP shows some movement towards recovery, but a stable level is attained withit five minutes after vessel occlusion; this verifies that the isotope clearance study is performed under steady state conditions (Fig. 4).

ELECTROENCEPHALOGRAPHY There were 11 instances in which focal slowing of EEG activity was observed during temporary occlusion of a vessel, and in each case the vessel being studied was considered unsuitable for ligation on the basis of CBF and ICAP measurements. In one case (patient no. 16, CCA clamp-Table 2) continuous EEG slowing appeared so abruptly after

\section{TABLE 4}

CEREBRAL BLOOD FLOW (CBF) AND INTERNAL CAROTID ARTERY PRESSURE (ICAP) DURING CLAMPING AND AFTER LIGATION $(\mathrm{N}=17, \mathrm{M} \pm \mathrm{SE})$

\begin{tabular}{lcc}
\hline & $\begin{array}{c}C B F \\
(\mathrm{ml} / 100 \mathrm{~g} / \mathrm{min})\end{array}$ & $\begin{array}{c}\text { ICAP } \\
(\mathrm{mmHg})\end{array}$ \\
\hline Vessel clamped & $42 \cdot 5 \pm 3 \cdot 1$ & $67 \cdot 4 \pm 5 \cdot 4$ \\
Vessel ligated & $42 \cdot 1 \pm 3 \cdot 2$ & $682 \pm 5 \cdot 1$ \\
\hline
\end{tabular}




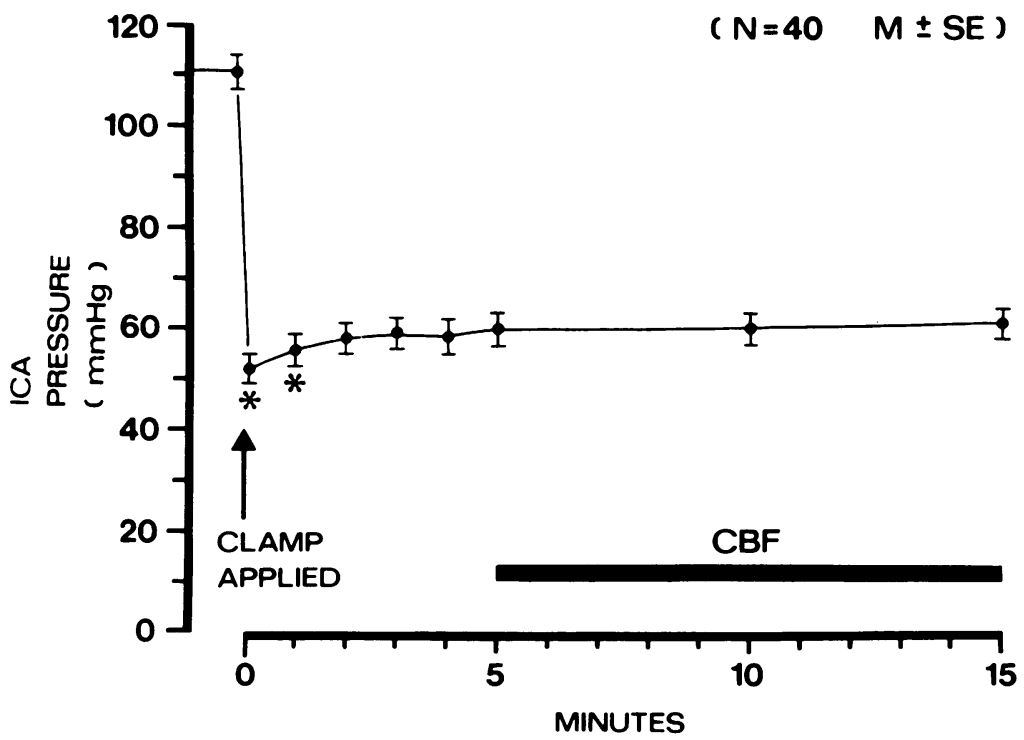

FIG. 4. Internal carotid artery pressure after clamp application. Asterisk indicates significantly different value from five minute level.

clamp application that the clamp was removed before a CBF measurement was undertaken. The mean CBF during vessel occlusion in cases showing focal EEG slowing was significantly less than that of cases without EEG changes during vessel occlusion $(P<0.01)$, but there was no graded correlation between the severity of the EEG changes and the level of CBF during carotid clamping. The small difference in ICAP between the two groups was not, however, significant (Table 3).

Slowing of EEG activity occurred at CBF levels of 12 to $39 \mathrm{ml} / 100 \mathrm{~g} / \mathrm{min}$, representing percentage reductions in CBF of $39-68 \%$, but levels of CBF as low as $17 \mathrm{ml} / 100 \mathrm{~g} / \mathrm{min}$, and percentage reductions as high as $69 \%$, were observed without any significant slowing of the EEG pattern. Similar discrepancies were noted in the analysis of the ICAP figures and EEG changes during clamping. It was, therefore, concluded that EEG recording alone was not reliable in predicting cerebral ischaemia in individual patients, although group differences could be demonstrated.

CAROTID LIGATION New criteria for recommending permanent carotid ligation were developed as the study proceeded and 17 of the 20 patients were accepted for ligation $(85 \%)$. Four- teen patients had the common carotid artery ligated and three underwent permanent occlusion of the internal carotid artery. When ligation was completed, CBF measurements made after tying the ligature were not significantly different from results obtained during temporary clamping of the same vessel (Table 4). Likewise, ICAP was similar when the vessel was occluded by a ligature compared with temporary occlusion (Table 4).

No patient suffered a permanent neurological deficit and there were no deaths. In two patients, temporary long-tract signs appeared during episodes of respiratory distress in the first six hours postoperatively, but both made a rapid recovery when oxygenation was restored. At the time of operation, each of these patients (nos 10, 11Table 2) had been regarded as having the maximum permissible reduction in CBF during clamping consistent with safe ligation.

\section{DISCUSSION}

Although carotid artery ligation was the earliest accepted form of surgical treatment for ruptured intracranial aneurysm (Schorstein, 1940), a reliable method for predicting the likelihood of cerebral ischaemia after ligation has been elusive.

Percutaneous digital compression of the caro- 
tid vessels in the neck (Matas, 1911), while either measuring limb power (McKissock, 1960) or making continuous EEG recording (Toole and Bevilacqua, 1963), has been used to assess the efficacy of the cross-circulation (Webster and Gurdjian, 1958); but this is not without its hazards (Nelson and Mahru, 1963) and false negative results due to inadequate compression are not uncommon.

Angiographic cross-filling with contralateral carotid compression has been used to establish that a satisfactory anatomical pathway exists across the anterior part of the circle of Willis. Jeffreys and Holmes (1971) tested 64 patients with ruptured posterior communicating artery aneurysms using this method. Of the 51 accepted for ligation, four $(8 \%)$ showed a temporary neurological deficit, but none had permanent ischaemia. This was not systematically studied in the present series, but one of the patients rejected from the series because of gross slowing of EEG activity and temporary hemiparesis during percutaneous carotid compression had good spontaneous angiographic cross-filling.

The most widely used method is occlusion of a carotid artery under local anaesthesia during which the patient is required to cooperate in neurological testing (Dandy, 1942; Mount, 1959; Heyman et al., 1960; Nishioka, 1966); although this method carries the advantage of simplicity, it may be unpleasant and produce stress for the patient, which is particularly undesirable after recent subarachnoid haemorrhage. The principal criticism of this approach, however, is that the onset of hemiparesis can be delayed for 24 hours or more after ligation (Voris, 1951; Nishioka, 1966). Gradual closure of a clamp over a period of several days has been advocated to meet this criticism (Mount, 1959); this method not only fails to provide protection from recurrent subarachnoid haemorrhage until the final stages of occlusion, but it appears to carry no advantage over immediate occlusion with regard to subsequent cerebral ischaemia (Brice et al., 1964).

Measurements of ICAP alone during temporary occlusion of the carotid vessels have been used to determine the safety of ligation (Sweet and Bennett, 1948; Bakay and Sweet, 1953; Odom et al., 1962). A difficulty has been that of defining the lower limits of safety. Moore and Hall (1969), measuring ICAP in 40 patients about to undergo carotid endarterectomy, used a lower limit of ICAP of $25 \mathrm{mmHg}$ to determine which patient should have a shunt inserted during the procedure. In view of the lower limit of systemic arterial pressure at which autoregulation of CBF can be maintained (about $60 \mathrm{mmHg}$ according to Harper (1966)), Boysen (1973) comments that many of these cases must have sustained reduced cerebral blood flow without clinical neurological change and she suggests a figure of $50 \mathrm{mmHg}$ as the critical level.

Observations of both ICAP and CBF after common carotid artery ligation have been made by Holmes et al. (1971). ICAP reached a stable value with a $38 \%$ reduction from control values, compared with $41 \%$ in the current study, and, although a different method of computing flow was used, the mean reduction in CBF 15 minutes after common carotid artery occlusion was $28 \%$, the same figure as was obtained in the current series. However, the complete recovery of $\mathrm{CBF}$ demonstrated by these authors 30 minutes afte vessel occlusion has not been confirmed. In the्के current study, the 17 patients who proceeded to $\delta^{\circ}$ permanent ligation provided the opportunity to measure CBF between five to 15 minutes and $2 \Phi$ to 30 minutes after vessel occlusion; no furthe $\overrightarrow{0} . \overrightarrow{0}$ change in CBF was seen (Table 4). ICAP has been shown to remain at a reduced level up to 18 hours after carotid ligation (Youmans et al., 1967).

Trojaborg and Boysen (1973) measured CBF and ICAP and recorded the EEG during temporary carotid clamping before 52 endarterectomies. EEG slowing was observed when CBF was in the range $16-22 \mathrm{ml} / 100 \mathrm{~g} / \mathrm{min}$, and ICAP between $29-50 \mathrm{mmHg}$. In the current study, the mean ICAP in the patients showing EEG slowing during clamping was $55.4 \pm 7.8 \mathrm{mmHg}$. That this value is higher than that noted by Trojaborg and Boysen may be partly explained by the fact that ICAP was measured within two minutes of clamp application in the Copenhagen series, but not until five minutes after clamping in the Glasgow patients, when ICAP will have risen significantly from the level immediately after clamping.

Patients with carotid artery stenosis and those with carotid artery aneurysms associated with subarachnoid haemorrhage may well have differences in cerebral autoregulatory capacity, 
but the most important difference between patients undergoing carotid endarterectomy and those having carotid ligation is that in the former group carotid occlusion is only temporary and the patient is recumbent and anaesthetized. The patient with a permanent carotid ligation must be able to withstand sudden changes in posture in the awake state. This difference should be allowed for in defining the lowest acceptable levels for ICAP and CBF during temporary occlusion.

Although measurement of ICAP during temporary clamping is of value in the selection of patients for permanent carotid ligation, many patients will be needlessly rejected if this measurement alone is used. In the current study, only 11 of the 20 patients would have been ligated if a level of $60 \mathrm{mmHg}$ had been used as the sole criterion. Similarly, use of CBF values alone would have led to fewer patients being accepted for ligation; only 12 of the 20 patients would have qualified for ligation by the $25 \%$ reduction rule, hitherto used to judge the likelihood of ischaemia.

Even after successul carotid ligation patients appear to be especially vulnerable to hypoxia or arterial hypotension, at least for a time, as evidenced by the two patients who developed temporary hemiplegia during respiratory distress postoperatively. Experimental findings in baboons subjected to carotid artery ligation by our colleagues in Glasgow have shown that, although resting CBF may be little affected, there is a significantly reduced cerebrovascular responsiveness to carbon dioxide and to hypoxia, with impaired autoregulation of CBF to a fall in blood pressure (Sengupta et al., 1972, 1974). This suggests the mechanism which makes patients vulnerable and emphasizes the importance of avoiding respiratory difficulties and arterial hypotension in the postoperative period. We recommend that patients are kept recumbent for 72 hours and elevated gradually thereafter.

\section{CONCLUSIONS}

The criteria derived from this study for predicting the likelihood of a neurological deficit after carotid ligation were as follows:

1. Carotid ligation is safe when the cerebral blood flow during temporary clamping is greater than $40 \mathrm{ml} / 100 \mathrm{~g} / \mathrm{min}$, but is unsafe when the cerebral blood flow during temporary clamping is less than $20 \mathrm{ml} / 100 \mathrm{~g} / \mathrm{min}$, regardless of the percentage reduction or the ICAP.

2. When the cerebral blood flow during temporary clamping is in the range of $20-40 \mathrm{ml} /$ $100 \mathrm{~g} / \mathrm{min}$, ligation is safe if the reduction from control values is less than $25 \%$, regardless of ICAP. If it is $25-35 \%$, ligation is safe provided the internal carotid artery pressure is greater than $60 \mathrm{mmHg}$ in a normotensive patient.

3. If facilities for measuring cerebral blood flow are not available, ligation is probably safe if the internal carotid artery pressure during temporary clamping is greater than $60 \mathrm{mmHg}$ in a normotensive patient.

The results of this study have led us to adopt the following modifications to our existing protocol.

1. Since ligation of the common carotid artery was indicated more often than internal carotid artery ligation, common carotid clamping is now performed first, after the initial control measurement. If the levels of CBF and ICAP are acceptable, common carotid ligation proceeds forthwith. If not, then a second control measurement and clamping of the internal carotid artery follow.

2. Since there was no difference between CBF values after clamping and after ligation, the postligation measurement is now omitted.

3. Since ICAP after clamping is stable after three minutes, the CBF measurement can start then.

These modifications have the desirable result of shortening the operative procedure without loss of any potentially useful information. This study provides a practical example of clinical and experimental research turned to therapeutic profit (Posner, 1972).

This investigation was supported by the Medical Research Council and forms part of the investigative programme of the MRC Group for the study of the Cerebral Circulation (Director: Professor Bryan Jennett). We thank the neurosurgeons of the Institute of Neurological Sciences, Glasgow, who referred their patients for treatment. We are indebted to $\mathrm{Mr}$ A. Dimmick and Miss F. Brydson for the EEG recordings and to the staff of the Clinical Physics Department for data processing. 


\section{REFERENCES}

Bakay, L., and Sweet, W. H. (1953). Intra-arterial pressures in the neck and brain; late changes after carotid closure, acute measurements after vertebral closure. Journal of Neurosurgery, 10, 353-359.

Boysen, G. (1973). Cerebral hemodynamics in carotid surgery. Acta Neurologica Scandinavica, Suppl 52, 49, 17.

Brice, J., Dowsett, D., and Lower, R. (1964). Some haemodynamic effects of carotid artery clamps. Journal of Neurology, Neurosurgery, and Psychiatry, 27, 580.

Dandy, W. E. (1942). Results following ligation of the internal carotid artery. Archives of Surgery, 45, 521-533.

German, W. J., and Black, S. P. W. (1965). Cervical ligation for internal carotid aneurysms: an extended follow-up. Journal of Neurosurgery, 23, 572-577.

Harper, A. M. (1966). Autoregulation of cerebral blood flow: influence of the arterial blood pressure on the blood flow through the cerebral cortex. Journal of Neurology, Neurosurgery, and Psychiatry, 29, 398-403.

Heyman, A., Tindall, G. T., Finney, W. H. M., and Woodhall, B. (1960). Measurement of retinal artery and intracarotid pressures following carotid artery occlusion with the Crutchfield clamp. Journal of Neurosurgery, 17, 297305.

Holmes, A. E., James, I. M., and Wise, C. C. (1971). Observations on distal intravascular pressure changes and cerebral blood flow after common carotid artery ligation in man. Journal of Neurology, Neurosurgery, and Psychiatry, 34, 78-81.

Jeffreys, R. V., and Holmes, A. E. (1971). Common carotid ligation for the treatment of ruptured posterior communicating aneurysms. Journal of Neurology, Neurosurgery, and Psychiatry, 34, 576-579.

Jennett, W. B., Harper, A. M., and Gillespie, F. C. (1966). Measurement of regional cerebral blood-flow during carotid ligation. Lancet, 2, 1162-1163.

Jennett, W. B., Miller, J. D., Cross, J. N., Barker, J., Wyper, D., and Harper, A. M. (1974). Cerebral blood flow measurements as a guide to the safety of carotid ligation. In Proceedings of 6th International Cerebral Blood Flow Symposium. (In press.)

Landolt, A. M., and Millikan, C. H. (1970). Pathogenesis of cerebral infarction secondary to mechanical carotid artery occlusion. Stroke, 1, 52-62.

McKissock, W., Richardson, A., and Walsh, L. (1960). 'Posterior-communicating' aneurysms. A controlled trial of the conservative and surgical treatment of ruptured aneurysms of the internal carotid artery at or near the point of origin of the posterior communicating artery. Lancet, 1, 1203-1206.

Matas, R. (1911). Testing the efficiency of the collateral circulation as a preliminary to the occlusion of the great surgical arteries. Annals of Surgery, 53, 1-43.

Moore, W. S., and Hall, A. (1969). Carotid artery back pressure: a test of cerebral tolerance to temporary carotid occlusion. Archives of Surgery, 99, 702-710.

Mount, L. A. (1959). Results of treatment of intracranial aneurysms using the Selverstone clamp. Journal of Neurosurgery, 16, 611-618.

Nelson, D. A., and Mahru, M. M. (1963). Death following digital carotid artery occlusion. Archives of Neurology, 8, 640-643.

Nishioka, H. (1966). Report on the cooperative study of intracranial aneurysms and subarachnoid hemorrhage. Section 8, part 1. Results of the treatment of intracranial aneurysms by occlusion of the carotid artery in the neck. Journal of Neurosurgery, 25, 660-682.

Odom, G. L., Woodhall, B., Tindall, G. T., and Jackson, J. R. (1962). Changes in distal intravascular pressure and size of intracranial aneurysm following common carotid ligation. Journal of Neurosurgery, 19, 41-50.

Posner, J. B. (1973). Newer techniques of cerebral blood flow measurements. In Cerebral Vascular Diseases. Transactions of the Eighth Conference, Princeton, New Jersey, 1972. pp. 145-162. Edited by F. H. McDowell and R. W. Brennan. Grune and Stratton: New York.

Rowan, J. O., Miller, J. D., Wyper, D. J., Fitch, W., Grossart, K. W., Garibi, J., and Pickard, J. D. (1974). Variability of repeated clinical measurements of cerebral blood flow using the Xenon ${ }^{133}$ intracarotid injection technique. In Proceedings of 6th International Cerebral Blood Flow Symposium. (In press.)

Sahs, A. L., Nibbelink, A. W., and Knowler, L. A. (1973). The cooperative aneurysm project: introductory report of a randomized treatment study. In Cerebral Vascular Diseases. Transactions of the Eighth Conference, Princeton, New Jersey, 1972. pp. 33-57. Edited by F. H. McDowell and R. W. Brennan, Grune and Stratton: New York.

Schorstein, J. (1940). Carotid ligation in saccular intra cranial aneurysms. British Journal of Surgery, 28, 50-70. 우 $\infty$ Sengupta, D., Harper, A. M., Deshmukh, V. D., Rowan of J. O., and Jennett, W. B. (1972). Effect of carotid arter席 ligation on the $\mathrm{CO}_{2}$ response in the baboon. European Neurology, 6, 369-372.

Sengupta, D., Harper, A. M., and Jennett, W. B. (1974) Cerebral blood flow in baboons following carotid ligation effects of hypoxia and hypotension. In Proceedings of 6th International Cerebral Blood Flow Symposium. (In press.) Sweet, W. H., and Bennett, H. S. (1948). Changes in interna carotid pressure during carotid and jugular occlusion and their clinical significance. Journal of Neurosurgery, 5, 178195.

Toole, J. F., and Bevilacqua, J. E. (1963). The carotid compression test. Evaluation of the diagnostic reliability and prognostic significance. Neurology (Minneap.), 13, 601-606.

Trojaborg, W., and Boysen, G. (1973). Relationship between EEG, regional cerebral blood flow and internal carotid artery pressure during carotid endarterectomy. Electroencephalography and Clinical Neurophysiology, 34, 61-69.

Voris, H. C. (1951). Complications of ligation of the internal carotid artery. Journal of Neurosurgery, 8, 119-131.

Webster, J. E., and Gurdjian, E. S. (1958). Carotid artery compression as employed both in the past and in the present. Journal of Neurosurgery, 15, 372-384.

Wyper, D. J., and Rowan, J. O. (1973). An on-line system for acquisition and processing of cerebral blood flow data. Computers in Biology and Medicine, 3, 55-62.

Youmans, J. R., Kindt, G. W., and Mitchell, O. C. (1967). Extended studies of direction of flow and pressure in the internal carotid artery following common carotid artery ligation. Journal of Neurosurgery, 27, 250-254. 